\title{
La Comunicación, nuevas tendencias.
}

\author{
Felisa Arribas PÉREZ \\ Universidad Complutense de Madrid \\ felisaarribas@telefonica.net
}

\section{Resumen}

La popularización, primero de Internet y posteriormente de las redes sociales ha obligado a las empresas a replantarse toda su estrategia de Comunicación.

Ya no es suficiente fabricar buenos productos, ahora la marca tiene que "enamorar" al consumidor y para conseguirlo nada más eficaz que la gestión de la Comunicación Corporativa a través de todas las herramientas, tanto tradicionales como de última generación.

En este artículo se analizan los nuevos medios y las relaciones que se establecen cada vez más interactivas entre las organizaciones y sus stakeholders.

\section{Palabras Clave:}

Comunicación, Redes Sociales, Internet, Tendencias, Publicidad online, Marketing online

\section{Communication, new trends}

\begin{abstract}
The popularization of the Internet and online social networks has forced companies to rethink their communication strategies.

Far are the times where focusing on good quality products was enough to reach success. Companies are becoming aware of their need to make customers love their products by using all communication tools, both traditional and cutting edge communication strategies.

This article explores new media and its growing presence in communications involving companies and their stakeholders.
\end{abstract}

Key Words: Communication, Social Media, Internet, Trends, Online Advertising, Online Marketing

Referencia normalizada:

Arribas Pérez, F. (2013) La Comunicación, nuevas tendencias. Historia y Comunicación Social. Vol. 18. $\mathrm{N}^{\circ}$ Especial Diciembre. Págs. 627-642.

Sumario: 1. Introducción. 2. Los Social Media. 2.1 La Web corporativa 2.2 El correo electrónico. 2.3 El blog corporativo. 2.4 Linkedin. 2.5 Facebook. 2.6 Twitter. 2.7 Buscadores en Internet 3. La medición del ROI en la Comunicación OnLine. 4. Tendencias del marketing que se llevarán en 2014.

\section{Introducción}

La aparición de internet y su popularización junto con el uso del ordenador personal, gracias a su abaratamiento, ha contribuido decisivamente a las nuevas formas de Comunicación. 
En el último lustro la utilización y uso masivo de los teléfonos móviles, en España hay 52 millones de líneas, como terminales de Internet ha sido un factor multiplicador del número de accesos y tiempo de conexión a la RED.

Estos acontecimientos han hecho cambiar la forma de gestionar la comunicación. Al mismo tiempo el concepto de empresa también ha evolucionado, desde la Revolución Industrial hemos pasado de la empresa basada exclusivamente en fabricar y vender sus productos, en la que la publicidad constituía prácticamente el único aliado, a la empresa que tiene que establecer un vínculo emocional con sus públicos, siendo imprescindible la gestión de sus activos intangibles, sobre todo la marca.

Ya no es suficiente fabricar buenos productos, ahora la marca tiene que "enamorar" al consumidor y para conseguirlo nada más eficaz que la gestión de la Comunicación Corporativa a través de todas las herramientas, tanto tradicionales como de última generación.

Anteriormente a la aparición de las Redes Sociales la relación de las empresas con sus públicos prácticamente se limitaba a la publicidad. La forma de hacer publicidad en medios tradicionales, prensa, radio y televisión ha evolucionado muy poco desde su aparición. Ahora han tenido que hacerlo impelidos por los nuevos medios.

La prensa se financiaba al $50 \%$ por la publicidad y por la compra directa, tanto ésta como aquella han sufrido unas caídas que en algunos casos ha provocado el cierre del medio, otros se han reconvertido en periódicos digitales y han aparecido nuevos medios digitales. La prensa tradicional ofrecía sus páginas en internet de forma gratuita hasta hace poco lo que según todos los expertos ha contribuido a acrecentar la crisis de la prensa. Es muy difícil recuperar clientes a los que has acostumbrado a recibir tu producto gratis.

La radio hace tiempo que busca nuevas fórmulas que le ayuden a compensar la bajada de los ingresos por publicidad tradicional. Esto ha supuesto que todas las cadenas estén orientando sus negocios hacia el área digital y el entorno online. Gracias a las redes sociales la interacción con el oyente es inmediata. Este medio se ha enriquecido y ha salido beneficiado. En algunos casos se ofrece la posibilidad de "ver" el programa a través de la web. Esta circunstancia demuestra que ningún medio tiene un único canal, ahora todos están interconectados y si los utilizamos adecuadamente podemos obtener grandes beneficios.

La televisión, el medio publicitario por excelencia no ha sido ajeno al uso de las redes. Cuando la televisión en color se implantó en España y había dos canales los índices de audiencia de los programas estrella eran de 15 millones, esa audiencia solo se ha conseguido recientemente en el minuto de oro de la final del mundial de fútbol, ahora un programa que llegue a los 3 millones se considera un gran éxito.

Las televisiones han visto en las redes sociales una forma de hacer más atractivo su producto, consiguiendo más publicidad. Las cadenas saben que ha cambiado la forma de estar ante la televisión. Es habitual ver la televisión a la vez que se interactúa con un móvil, pudiendo generar un tráfico interesante para la cadena y sus anunciantes. 
Esta forma tan directa de comunicación tiene el inconveniente de poder crear una opinión negativa mayoritaria obligando en algunos casos a cambiar de estrategia. Ocurrió con la entrevista que se realizó a la madre de un delincuente causando una ingente cantidad de opiniones negativas contra la cadena y sus anunciantes. Las marcas se vieron obligadas a retirar la publicidad y de hecho el programa en el que se emitió ha desaparecido.

Controlar, no como censura sino como gestión, la comunicación en las redes es primordial. Ya se sabe si no hablamos nosotros de nosotros, hablarán otros. Si cometemos un error hay responder rápidamente, no vale el clásico "ya escampará", normalmente no escampa sino que se convierte en tsunami.

\section{Los social media}

Algunos datos (según el informe Social Media Marketing Industry) que demuestran el poder de las redes sociales:

Las redes sociales forman parte de las estrategias de marketing de las empresas en el $79 \%$ de los casos.

En Estados Unidos los usuarios de internet destinan el 27\% de su tiempo online a las redes sociales.

Los usuarios de móvil, en Estados Unidos, invierten el 15\% de su tiempo en conectarse a los social media.

Las redes sociales generan el doble de seguidores que otras acciones de marketing.

La tasa de conversión de estos seguidores es un 13\% más elevada que los conseguidos por otros medios.

El 21\% de los responsables de marketing afirma que las redes sociales han ganado especial importancia dentro de su estrategia de marketing en los últimos 6 meses. El $62 \%$ de los responsables de marketing dedican al menos 6 horas semanales a actualizar sus perfiles sociales.

Las mujeres son especialmente activas en las redes. El 48\% suele consultar regularmente los perfiles sociales de sus marcas preferidas, frente al $43 \%$ de los hombres.

El 23\% de los responsables de marketing tiene previsto aumentar su presupuesto destinado a blogging y social media este año. Supone un $9 \%$ más que el año anterior.

Las redes sociales son una fuente fiable para los usuarios. Casi la mitad, el $46 \%$, tiene en cuenta la información que obtiene a través de ellas.

Analizando estos datos ninguna empresa debería quedar al margen de la gestión de las redes como parte de su Comunicación. 
Dependiendo del tipo de sector al que pertenezcamos y de los objetivos que queramos conseguir tendremos que utilizar diferentes tipos de herramientas:

La web corporativa

El correo electrónico

El blog corporativo

Linkedin

Facebook

Twitter

Buscadores, especialmente Google

\subsection{La web corporativa}

Debería ser el principal soporte de nuestra estrategia en redes sociales. En las redes sociales cada una pone sus condiciones, incluso hasta llegar al extremo del cierre, pudiendo perder toda la información, mientras que en nuestra web somos nosotros los que controlamos al 100 por 100 esta herramienta.

Cuando se generalizó el uso de internet las empresas se debatían sobre si era conveniente o no tener una web corporativa, ahora cualquier empresa que quiera ser competitiva y que se relaciona adecuadamente con sus públicos tiene su web.

Se ha convertido en una herramienta muy valiosa para mostrar la empresa y ofrecer sus productos y servicios. Debe estar alineada con otras actuaciones en las redes sociales, es conveniente que éstas remitan a la web.

Según el informe "ePyme” realizado por Fundetec y ONTSI, la página web corporativa alcanza una penetración media del $71 \%$ entre las pymes y grandes empresas y un $28.6 \%$ entre las microempresas con acceso a Internet.

En cuanto a pymes, 6 de los 10 sectores analizados superan la penetración media. Sectores como hoteles, campings, agencias de viajes e informática, telecomunicaciones y servicios audiovisuales, alcanzan penetraciones superiores al $90 \%$, ya que son sectores cuyo público objetivo demanda más la búsqueda de información vía online.

Todos los sectores opinan que la web es la mejor carta de presentación de la empresa, sin embargo, en las microempresas todavía no es una herramienta utilizada en la empresa, ya que solo los dos sectores anteriores alcanzan el 50\% de penetración, el resto no llega al $40 \%$.

Lo más importante para que la web sea eficaz es que esté bien posicionada en los buscadores, debemos elegir palabras clave para ser encontrados fácilmente.

Las nuevas webs tienen un diseño más limpio, colores planos y líneas rectas. Google está imponiendo los círculos, ha vuelto el "scroll", los diferentes elementos se mueven a distinta velocidad creando efectos visuales muy interesantes. Parece que 
asistimos al fin del "skeumorfismo", asociar a las nuevas herramientas rasgos de sus antecesores, que se oiga click cuando hacemos una foto o el ruido de pasar hojas en un iPad.

\subsection{El correo electrónico}

Es la primera herramienta que se utilizó de forma masiva en internet.

El mail permite enviar y recibir mensajes de forma inmediata, quedando registrados los mensajes. Forma siempre parte de la tarjeta de visita, no se concibe una empresa e incluso una persona sin correo electrónico.

Sin embargo hay opiniones encontradas sobre su futuro. Hay quien opina que paulatinamente será sustituido por las redes sociales hasta su desaparición, otros piensan que no es tan fácil que desaparezca.

Algunas razones que compartimos con eNubes.com:

Casi todas las webs y sites piden el correo electrónico para registrarte, no el perfil de Facebook, ni de Twitter.

Las redes sociales utilizan el correo electrónico como soporte y para contactar al usuario, enviarle actualizaciones, conseguir que entre en la red, recordarle eventos, etc.

Hay mucha gente que no está en las redes sociales y sólo tiene correo electrónico.

El correo electrónico es uno y universal y las redes sociales son miles.

Incluso las redes sociales, sus directivos y los estudios que éstos realizan, reconocen la importancia del correo electrónico.

Las campañas de e-mail marketing siguen siendo una de las principales herramientas de marketing on-line.

Las redes sociales son herramientas propiedad de empresas, no son inherentes a internet, como es el correo electrónico.

Es complicado tener dos perfiles en las redes sociales, uno profesional y otro personal. Por el contrario, sí puedes tener dos o más correos electrónicos diferenciados.

La gente sigue enviando cartas y eso que parecía que iban a desaparecer y a ser reemplazadas por el correo electrónico. Por tanto, aunque las redes sociales estén creciendo de forma acelerada, no llegarán a sustituir al correo electrónico a medio plazo.

\subsection{El blog corporativo}

Es un sitio web periódicamente actualizado que recopila textos o artículos de forma cronológica, de uno o varios autores cuyo objetivo desde el punto de vista empresarial es dar mayor visibilidad a la marca. Para que tenga éxito es imprescindible que 
aporte valor y que siempre esté actualizado. Se suele utilizar para anunciar las novedades. Junto con la web corporativa es el elemento fundamental de una estrategia de comunicación sólida y a largo plazo en redes sociales.

Los blogs son la tercera fuente digital en influencia sobre las decisiones de compra de los consumidores. Los resultados del último estudio sobre influencia digital de Technorati así nos lo muestran.

Los blogs son excelentes repositorios de información institucional, sectorial o promocional, nos ayuda a ganar visibilidad y reputación y es una magnífica carta de presentación para inversores, clientes y colaboradores.

Es muy útil una estrategia de acercamiento a los blogueros más influyentes. Los consumidores les perciben como sinceros al hablar de productos y servicios. Para las marcas es mucho más interesante confiar en personas que tengan relaciones estrechas con sus comunidades que comunidades inmensas.

También aparecen detractores de esta herramienta diciendo que rápidamente será sustituida por Facebook, Linkedin, u otras plataformas. Sin embargo, en esta nueva era el contenido sigue siendo el rey y para esto los blogs son su mejor vehículo.

Algunos estudios nos ofrecen datos significativos, como que las empresas poseedoras de un blog corporativo tienen un $97 \%$ más de aceptación y un 55\% más de visitas en sus sites. El 37\% de los publicistas coinciden al afirmar que los blogs son el contenido que ofrece el marketing online con más valor. Y es que lo que buscan los usuarios no es exclusivamente información sino también contenido. Los blogs tienen una influencia un 63\% mayor en la toma de decisiones de los compradores que las revistas.

Con este elemento se puede poner en práctica la unión de elementos tradicionales con los nuevos. Convocatorias de prensa en las que aunemos periodistas y blogueros.

\subsection{Linkedin}

En Linkedin se puede publicar información personal y profesional, y a través de estos perfiles generar redes y contactos. También se pueden publicar debates, artículos, noticias, preguntas, respuestas y grupos de interés.

Es la red social profesional por excelencia tiene más de 225 millones de usuarios en todo el mundo y 5 millones en España.

El secreto de Linkedin es la filosofía de los seis grados de separación, que permite a las personas conectarse a una red más amplia, encontrar a los demás y que los demás los encuentren a ellos. Desde el punto de vista personal potencia la visibilidad de los perfiles profesionales de los miembros.

En cuanto a las empresas:

- Permite acceder a información más detallada de potenciales empleados. 
- Promueve el networking.

- Permite contactar con nuevos clientes y proveedores.

- Potencia el branding de nuestra empresa.

- Ayuda a la gestión de la reputación online corporativa.

- Permite integrar funcionalidades de otras redes sociales.

La comunicación corporativa se puede potenciar mediante:

- Creación de un perfil de empresa

Los perfiles de empresa son como páginas de empresas de Facebook. En dichas páginas se puede insertar información corporativa, el logo, la dirección de la página, los servicios o especialidades de la empresa, etc. Adicionalmente el perfil de empresa se va actualizando automáticamente con los nombres de los empleados de la empresa que poseen previamente una cuenta de usuario en Linkedin.

Linkedin posee un buscador interno que es muy utilizado por los usuarios para encontrar empresas u organizaciones. Si tenemos bien redactado el perfil de nuestra empresa tendremos muchas posibilidades de salir bien posicionados en los resultados del buscador de Linkedin para palabras clave relacionadas con la actividad de nuestra empresa.

- Creación de grupos

Similar a los grupos de Facebook, podemos crear grupos especializados en un tema. En dicho grupo se pueden añadir artículos, noticias, debates, preguntas y ofertas de empleo. Lo interesante de estos grupos es que los usuarios de Linkedin que se hagan miembros recibirán cada 7 o 15 días un boletín con la información subida recientemente a dicho grupo. Se tiene un nuevo canal de comunicación muy poderoso.

\section{- Preguntas y respuestas}

En esta sección se puede plantear tanto posibles preguntas, como aportar nuestros conocimientos respondiendo preguntas que plantean otras personas. En muchas de las preguntas que hacen los usuarios están las de pedir recomendación sobre una empresa que están buscando para contratarles un trabajo. Nuestra labor es monitorear preguntas relacionadas con nuestro sector y responderlas dando un argumento profesional y ofertando nuestros servicios.

- Anuncios patrocinados

Además de los servicios gratuitos, Linkedin ofrece la posibilidad de publicitarse en la red a través de anuncios de texto y banners publicitarios. Podemos basar nuestros anuncios en criterios tales como tamaño de la compañía, cargo en la empresa, sector al que pertenece, experiencia, edad, o localización geográfica de los usuarios a los que nos dirigimos. 
Linkedin no es la única red profesional. Existen otras redes de similar funcionamiento y que también gozan de alta popularidad tales como Xing y Viadeo.

\subsection{Facebook}

Es la mayor red social del mundo creada en 2004.

Facebook es muy influyente a la hora de aumentar el tráfico web. Las empresas que consiguen más de 1000 "me gusta" reciben unas 1400 visitas más al día.

Según el informe Social Media Marketing Industry de 2013, el 49\% de los responsables de marketing se decantaría por Facebook si solo pudiera estar en una red social y además el $52 \%$ de las empresas ha conseguido clientes a través de esta red.

En los últimos tiempos se han subido 250.000 millones de fotos, con un promedio de 350 millones de imágenes al día, superando a todos los sitios especializados en el almacenamiento de fotos. El éxito de Facebook no solo se debe a las ingentes cantidades de fotos que se suben sino también a los contenidos. Sus usuarios tiene un alto nivel de interacción. Cada día generan más de 4,5 millones de "Me gusta" y envían más de 10.000 millones de mensajes a través de los cauces internos de Facebook, esto es, el sistema de mensajería privada.

El alto porcentaje de penetración de la telefonía móvil inteligente podría haber jugado un papel fundamental en este éxito.

Hay tres formas de estar en Facebook:

- El perfil personal, creado para las personas. Nunca se debe crear un perfil de una organización bajo la opción de perfil personal.

- Los grupos, creados por usuarios que desean reunir a personas en torno a un tema común.

- Las páginas, sirven para promocionar productos, organizaciones o figuras públicas. Esta es la opción adecuada para empresas y organizaciones.

Una empresa debería estar en Facebook cumpliendo algunos requisitos:

- Tener una estrategia de contenido y que agrupe al resto de las redes donde la marca esté presente.

Para organizar el contenido, y las fechas en las cuales estos temas serán publicados, es posible utilizar herramientas como HootSuite. Esto ayudará a obtener una visión más amplia de qué se va a publicar con días o semanas de anticipación.

- Actualizar la página de manera frecuente

Es necesario publicar contenidos de manera periódica.

La cantidad de veces a publicar dependerá del tipo de producto o servicio ofrecido, pero el objetivo principal será el de mantener una presencia constante. El contenido de calidad hará que los usuarios de Facebook se sientan más inclinados a hacer clic 
sobre el botón "Me Gusta", para mantenerse informados de las últimas novedades que sean publicadas.

- Dar respuesta a los comentarios de los seguidores.

Aquellos seguidores de una Página en Facebook que publiquen preguntas esperarán recibir una respuesta. Es importante resolver estos interrogantes dentro de un plazo determinado. De lo contrario, otros seguidores podrían obtener la impresión de que esta Página no tiene ningún interés en conectarse con quienes la siguen.

- Crear páginas en lugar de perfiles personales

El primero, y uno de los peores, errores que puede cometer una empresa, marca o incluso un artista al momento de conectarse con sus seguidores es crear un perfil personal en vez de una página o más. Una página en Facebook permitirá a quien la administre conocer, entre otras cosas, información detallada de sus seguidores. Este tipo de datos será luego accesible desde el panel de administración para páginas en Facebook.

- Los contenidos publicados deben ser originales e inéditos

Que una foto se encuentre disponible en Internet, en un blog o en una red fotográfica como Flickr no significa que sea gratuita. Lo mismo ocurre con contenido que ha sido escrito y publicado en otros medios. Muchas marcas en Facebook sin embargo publican fotos, imágenes y videos que pertenecen a otros creadores, sin contar con su consentimiento, lo que constituye otro error grave.

Realizar este tipo de acciones puede traer graves problemas legales para la marca, además de conllevar un serio problema de relaciones públicas.

- Tener a un especialista que comprenda cómo funciona Facebook.

Una Página en Facebook puede ser el primer intento de una marca para conectarse con sus seguidores. También puede formar parte de una estrategia de Comunicación Corporativa desarrollada con anterioridad. Sin importar su origen, es necesario que aquellas personas autorizadas para publicar actualizaciones comprendan cómo funcionan las diferentes herramientas de Facebook.

Los especialistas encargados de manejar Facebook deben comprender conceptos relacionados con la comunicación y las tecnologías en las cuales se basan estas redes. Esto evitará posibles problemas al momento de publicar actualizaciones. También ayudará a la marca a estar informada acerca de la evolución de estas redes y la aparición de nuevas oportunidades para ser aprovechadas.

- Moderar el contenido publicado por los seguidores de una página.

Dependiendo de cómo haya sido configurada, los seguidores de una página podrían tener acceso a publicar su propio contenido en ella. Imágenes, comentarios y enlaces que no sean moderados y controlados podrían atentar contra leyes locales, ofender a otros seguidores y además podría dar la impresión de que la marca apoya y aprueba este tipo de mensajes. 


\subsection{Twitter}

Es una de las herramientas sociales más populares.

La red ha ganado popularidad mundialmente y se estima que tiene más de 200 millones de usuarios, generando 65 millones de tuits al día y maneja más de 800.000 peticiones de búsqueda diarios.

Permite enviar mensajes de texto plano, con un contenido de 140 caracteres, por defecto los mensajes son públicos, pudiendo difundirse privadamente mostrándolos únicamente a unos seguidores determinados.

Un aspecto muy interesante son los "trending topics", temas de moda que alcanzan una gran número de seguidores. Cuando mucho usuarios agrupan una temática para convertir una noticia en "trending topic" se pone delante \# (hastag).

La comunicación en las empresas puede utilizar Twitter para:

Desarrollar y promover la marca.

Interactuar con los clientes.

Hacer ruido mediático y reforzar un evento, se puede "twittear" en tiempo real lo que sucede en cada momento.

Hacer llegar contenidos como seminbarios, cursos, blogs, ...

Incluso generar oportunidades de negocio.

\subsection{Buscadores de internet}

Cada vez más, los llamados buscadores son el medio para que los usuarios accedan a las páginas que les interesan. Incluso en páginas con URL (dirección de la página) conocida, no se teclea en muchos casos esta si no una parte del nombre para localizarla a través del buscador.

Estos buscadores, se identifican ya por muchos usuarios de forma que se oye con frecuencia la palabra "googlear" en lugar de "navegar" o usar Internet.

Esto convierte a los buscadores en la herramienta más usada en Internet, a la página principal del buscador más popular en la más accedida y a la empresa que lo posee en la que mayor información tiene sobre los usuarios de la Red.

Google es el buscador más utilizado. A nivel mundial, según las estadísticas de Netmarketshare, tiene más del $80 \%$ del mercado a muchísima distancia de sus seguidores, Yahoo (6,5\%), Baidu $(6,06) \%$ y Bing $(4,43 \%)$ y). En España esto es aún más pronunciado ya que Google prácticamente monopoliza el uso con un $95 \%$ de los accesos de búsqueda.

Si a esto se suma que posee el más importante canal de vídeo (Youtube) que soporta casi la mitad de reproducciones de vídeo online de Internet, Google se convierte en 
una formidable plataforma publicitaria para cualquier empresa comercial y el caso más interesante a ser considerado en las estrategias de comunicación.

Google, basa su estrategia de obtención de beneficios precisamente en la publicidad. Para ello ha creado varios programas, especialmente el que denomina AdSense.

AdSense es un servicio de Google por el cual el webmaster de un sitio web reserva espacios en sus páginas en las que se insertan anuncios basados en texto, llamados AdWords y recibe una cantidad de dinero por cada 'clic' que el visitante haga sobre el anuncio. Una pieza de software que se inserta en la página conecta con el servidor Google y coloca el anuncio que Google le devuelve.

Estos anuncios se eligen por su relación con el tema de la página y el historial de navegación del usuario que ha entrado en ella de forma que se consiga un máximo de interés en el objeto del anuncio por parte del usuario que lo recibe.

La facilidad para realizarlo y la obtención de beneficios ha movido a millones de webmasters a incluir sus páginas en este programa.

Así mismo, Youtube tiene un programa similar para presentar anuncios relacionados con sus vídeos

Las ventajas para el anunciante, según Google, vienen dadas por varios factores:

Solo se paga por clic efectivo o por visualización del video publicitario, es decir solo si el usuario muestra interés en el anuncio.

Las plataformas en las que se recibe el anuncio son todas las que permiten acceso a Internet: Ordenadores personales, teléfonos móviles, tablets, etc.

El anuncio llega a aquellas personas que, a priori, pueden estar más interesadas, basándose en su historial de navegación y en el tema general de la página accedida.

Además Youtube permite la creación de "canales corporativos".

Todo esto convierte a Google en el mayor proveedor de espacios publicitarios del mundo, con una preeminencia aplastante en todo lo que son medios online.

Google sabe mucho, más de lo que la mayoría piensa, de cada usuario de Internet. A través de su buscador que registra sus preferencias con las búsquedas y elecciones que hace. De sus canales de vídeo que saben los que reproduce. De su aplicación GoogleMaps, que conoce la planificación de sus desplazamientos y, en muchos casos, en que zona vive y trabaja.

Estos datos, que le han servido para tener el buscador más utilizado gracias a su capacidad para responder de manera personalizada a nuestras búsquedas, le sirven también para discriminar los usuarios desde el punto de vista publicitario.

Otro elemento a tener en cuenta sobre Google y otros buscadores es la importancia que tiene que nuestra web aparezca entre los primeros resultados que se devuelven al usuario cuando hace preguntas relacionadas con ella. Si un usuario pregunta por un producto o servicio o busca una información relevante, es infrecuente que consulte 
otros resultados que los que el buscador devuelve en la primera página, especialmente si ya encuentra respuestas válidas en ella. De ahí la importancia de que una web esté correctamente gestionada en su relación con los buscadores.

En este contexto, Google y otros buscadores ofrecen publicidad en forma de "enlaces patrocinados" por los cuales aparecerán en la primera página enlaces a la web de quien los contrata en consultas relacionadas con los temas que considera que muestran un posible interés en sus productos o servicios.

\section{La medición del ROI}

La dificultad para medir el ROI (Retorno de la Inversión) ha sido uno de los argumentos esgrimidos en contra de las estrategias de comunicación soportadas en Internet y en las redes sociales, pero a día de hoy este argumento ha perdido mucho peso, gracias a la aparición de numerosas herramientas, generales y especializadas en redes concretas.

Cualquier estrategia de comunicación basada en medios online necesita de una evaluación de su efectividad y esta solo se puede conseguir en base a la obtención de datos numéricos que pongan en valor la estrategia de comunicación de la organización.

El tráfico Web, dispone de una herramienta gratuita ofrecida por Google: Google Analitycs, que a pesar de su gratuidad, da una información exhaustiva sobre los accesos a nuestra web, el número de usuarios que acceden, el tiempo de permanencia, las páginas visitadas, la segmentación geográfica, tipo de navegador, sistema operativo, etc.

Todos estos datos se consultan online con la división periódica y estadística que se desee.

Google Analitycs, no siendo una herramienta inicialmente diseñada para redes sociales, sin embargo también ayuda a ver su efectividad ya que discrimina la procedencia del tráfico que llega a nuestra Web. Podemos saber cuántos accesos hay por entrada directa (nuestra URL tecleada en el navegador), cuantos vienen de cada uno de los buscadores, cuantos proceden de enlaces desde cada una de las redes sociales, cuantos desde enlaces colocados en otras webs y cuantos desde anuncios en la red contratados por nuestra organización.

Hay numerosas herramientas, algunas de pago muy completas para obtener cantidad y segmentación del tráfico de nuestra Web como Analitycs, clicky, Woopra, Piwik, Starcounter...

En las Redes Sociales, es algo más complejo ya que no solo es tráfico, se trata también de fidelizar a nuestros públicos y mantener un cierto feedback con ellos. 
También de medir la viralidad de nuestra campaña en cuanto a reenviar, comunicar o compartir con terceros nuestros artículos e informaciones.

Recientemente han surgido numerosas herramientas, algunas son de uso más general y pueden utilizarse para medir nuestras campañas en diferentes blogs y redes sociales. Unos ejemplos como, Tinker y HootSuite.

Otras están diseñadas de manera más específica para medir la efectividad de nuestra presencia en una red social concreta. Para Twitter existen infinidad, como Twitstat, Twit Search y HashTags. Para Facebook, Faceboostic o Facebook Lexicon.

Hay también herramientas específicas para blogs como Blogpulse o Google Blog Search.

Quien utiliza una estrategia de comunicación en Social Media espera un retorno de su inversión, como en cualquier otra. Este retorno puede ser en forma de tráfico hacia nuestra Web, fidelización, reforzamiento de la marca, identidad digital, suscripciones, etc. La medida de estos factores no siempre es fácil, incluso con las herramientas adecuadas para ello citamos 10 formas de medir el ROI que pueden ser útiles, según los objetivos que se marque cada organización. Extraídos del Blog isragarcia.es.

Oportunidad de conversión

Monitoriza la afluencia de tráfico a tu web desde tus redes sociales y lista las que más tráfico generan. Considera medir también los links de referencia a tu sitio.

Duración de Engagement

Para algunas empresas o negocios la duración del engagement (vinculación emocional) es más importante que las visitas. Si la gente visita tu sitio web o blog desde las plataformas sociales ¿cuánto tiempo permanecen en ellas?(Sigue que páginas visitan y cuáles son las más vistas)

Porcentaje de rebote

La información que se demanda tiene que ser encontrada rápidamente, porque si no, los usuarios dejarán el sitio/blog inmediatamente.

Incremento de comunidad y número de los usuarios activos

Esta es la porción de las redes sociales de tu negocio (twitter, facebook, etc.) que interactúan con tu contenido social media. ¿Está nuestra comunidad creciendo? Y lo más importante ¿hay interacción entre la comunidad y los objetos sociales?

Activad en nuestra comunidad

Comparar el ratio de miembros activos con el de miembros totales

Conversiones

El objetivo es que nuestra comunidad se convierta en clientes

Menciones de marca 
Si tienes una comunidad activa y que habla de ti y tu negocio. Mide y monitoriza tanto las menciones positivas como las negativas.

Lealtad

Tu comunidad, interactúa constantemente, comparte contenido y links, menciona tu marca, evangeliza.

Tenemos que medir cuál es la frecuencia de redistribución.

Viralidad

Tu comunidad esta compartiendo tweets y actualizaciones Facebook relacionadas con tu negocio, pero están siendo redistribuidas por sus propias redes.

Interacciones blog

Los blogs son una parte del ecosistema social media marketing, pero sólo si permites comentarios e interactúas con los lectores respondiéndoles. Si es así, considera poner un botón "compartir" entonces sigue a las referencias de vuelta desde esos sitios.

\section{Tendencias de marketing que se llevarán en 2014}

2013 se caracteriza por la consolidación de las redes sociales como vía para llegar al público objetivo. Forman parte de la estrategia de comunicación de la empresa. El ROI seguirá siendo uno de los grandes desafíos.

Todavía muchas marcas se plantean la utilización de las redes sociales, sin embargo en 2014 muchas más empresas las utilizarán para dar respuestas rápidas a los clientes.

El marketing de contenidos seguirá creciendo porque se ha revelado como una herramienta ideal para generar confianza.

La imagen alcanzará todavía más relevancia y protagonismo. De hecho los blogs y post más compartidos son aquellos que combinan texto con imágenes.

El vídeo será la nueva revolución del contenido en 2014. Cisco estima que en 2015 el $85 \%$ del tráfico en internet estará basado en vídeos.

La migración al móvil es una realidad. EMarketer espera que el 67,6\% de los usuarios de Facebook consulten sus perfiles a través de dispositivos móviles.

Que nuestra marca tenga presencia en internet, en todas sus acepciones, será vital para dar a conocer y consolidar la propia marca. 


\section{Referencias Bibliográficas.}

Libros

ARRIBAS,F.; BOTEY, J.; ARCEO, A. (coord.), (2012). El portavoz en la comunicación de las organizaciones, Alicante, Universidad de Alicante.

BRANDES, Ulrik, y ERLEBACH, Thomas (Eds.). (2005). Network Analysis: Methodological Foundations Berlin, Heidelberg: Springer-Verlag.

CASALEGGIO, Davide (2008). TU SEI RETE. La Rivoluzione del business, del marketing e della politica attraverso le reti sociali. Associati

COZ FERNANDEZ, José Ramón y FOJON CHAMORRO, Enrique (2010). Modulo de Madurez para la Privacidad de una Red Social Virtual. Lulu.com

DIRCOM (2013): Manual de la Comunicación. DIRCOM, Madrid, Asociación de Directivos de Comunicación.

FUETTERER, Stephan (2010): Mi Comunidad ... ¿Me quiere o no me quiere?, Madrid, Advantia Comunicación Gráfica, S.A.

LIGON, Ethan; SCHLECHTER, Laura, The Value of Social Networks in rural Paraguay, University of California, Berkeley, Seminar, March 25, 2009 , Department of Agricultural \& Resource Economics, College of Natural Resources, University of California, Berkeley

SUAREZ,A.; (2012) Desnudando a Google, Barcelona, Deusto.

WENG, M. (2007). A Multimedia Social-Networking Community for Mobile Devices Interactive Telecommunications Program, Tisch School of the Arts/ New York University

Publicaciones Web:

http://www.contunegocio.es/marketing/blogs-y-pymes-moda/ [30/10/2013]

http://gesblog.com/como-medir-roi-y-otros-desafios-social-media/ [30/10/2013]

http://isragarcia.es/10-formas-de-medir-el-roi-en-social-media [29/10/2013]

$\mathrm{http}: / /$ www.youtube.com/watch?v=3_vbr3u-sQU [10-10-2013]

$\mathrm{http} / /$ www.youtube.com/watch? $\mathrm{v}=\overline{\mathrm{O}} \mathrm{wWbvdllHVEhttp://es.slideshare.net/binime-}$

lis94/hitos-de-la-comunicacin-9749540 [10-10-2013]

http://es.wikipedia.org/wiki/Tecnolog\%C3\%ADas_de_la_informaci\%C3\%B3n_y_

la_comunicaci\%C3\%B3n\#Redes_de_televisi.C3.B3n [0̄7-10-2013]

http://www.cluetrain.com/ [05-10-2013] 


\section{La autora}

Felisa Arribas. Doctora en Ciencias de la Información y profesora en el área de Comunicación Audiovisual y Publicidad en la Universidad Complutense de Madrid. Ha sido Directora de Comunicación de la Escuela de Organización Industrial y de BID 12 Bienal Iberoamericana de Diseño. DI MAD. Directora del Seminario "Creatividad en Vivo" realizado por la Facultad de Ciencias de la Información y la agencia Mc.Cann Erickson. Miembro del grupo de investigación de la UCM "ESAVICOM". Colaboradora habitual de medios de comunicación. Miembro de DIRCOM (Asociación de Directivos de Comunicación). 